\title{
Perancangan Website Sistem Informasi Penjualan pada Anita Kurnia Boutique Malang
}

\author{
Anggraeni Sari Rumpoko ${ }^{1}$, Gunawan Budi Sulistyo ${ }^{2}$ \\ Universitas Bina Sarana Informatikanstitusi/Afiliasi \\ anggraenirumpoko@bsi.ac.id \\ gunawan.gnw@bsi.ac.id
}

\begin{abstract}
Seiring dengan perkembangan teknologi informasi yang semakin modern saat ini, mendorong para pelaku bisnis (pengusaha) untuk berlomba-lomba dalam memasarkan produk-produk mereka menggunakan fasilitas internet seperti website. Anita Kurnia Boutique adalah perusahaan yang bergerak di bidang jasa yang menjual pakaian wanita dengan kualitas premium dan reguler. Pakaian yang dijual oleh Anita Kurnia Boutique lebih mementingkan kualitas bahan pakaian. Untuk mengatasi masalah tersebut maka dibuatlah website Anita Kurnia Boutique sebagai media informasi bagi pelanggan. Dengan adanya website ini dapat memudahkan Anita Kurnia Boutique dalam memberikan informasi kepada user dan diharapkan dapat meningkatkan omset penjualan Anita Kurnia Boutique. Rancangan pembuatan website Anita Kurnia Boutique menggunakan software Adobe Dreamweaver CS6, Xampp, dan Adobe Photoshop CS3. Sedangkan dalam pengujian unit menggunakan Black Box Testing. Dengan website e-commerce ini, dapat membantu pelanggan dan masyarakat untuk mendapatkan informasi tentang Anita Kurnia Boutique, area pemasaran yang dapat menjangkau hingga ke daerah lain, dan juga dapat melakukan belanja online.
\end{abstract}

Keywords: Perancangan Website, Sistem Informasi, E-Commerce

\section{PENDAHULUAN}

Perkembangan teknologi informasi yang semakin modern dalam beberapa tahun terakhir ini, telah membawa dampak pada berbagai aspek kehidupan, termasuk di dalamnya berkembang juga internet. Intenet itu sendiri adalah jaringan (interconected-network) merupakan sekumpulan jaringan yang menghubungkan berbagai macam situs. Intenet juga memiliki sumber daya informasi untuk jutaan pemakai di seluruh dunia. Oleh karena itu, perkembangan informasi telah memunculkan situs internet sebagai situs yang paling banyak digunakan oleh masyarakat diseluruh dunia.

Penggunaan internet pada jaman teknologi informasi modern ini telah menjadikan banyak perusahaan atau bisnis menggunakan internet sebagai media untuk berjualan satu diantaranya bisnis online dibidang fashion. Bisnis dibidang fashion adalah bisnis mode pakaian yang beberapa tahun belakangan ini telah mengalami perkembangan yang fantastik mengingat peminat dibidang fashion adalah kaum hawa yang sangat perduli akan penampilan, baik penampilan dari luar maupun penampilan dari dalam.

Kemajuan dalam bidang fashion menjadikan usaha dibidang ini semakin maju karena produk fashion selalu mengalami perubahan dari tahun ke tahun seiring dengan gaya hidup manusia yang selalu berubah-ubah terutama para wanita yang selalu mendambakan berbagai pakaian atau mode yang unik, serasi, mewah, dan berkualitas serta bermerek. Fashion telah mampu mengubah citra diri seorang manusia sehingga pantas perkembangannya mengalami kemajuan dengan munculnya berbagai jenis fashion dipasar dan peminatnya pun beragam tergantung dari jenis dan kualitas fashion yang dijual.

Dalam hal ini kemajuan pada bidang fashion sehingga membuat orang-orang mulai memanfaatkan peluang tersebut dengan mendirikan toko yang berjualan beragam jenis pakaian perempuan, selain itu hadirnya departement store yang berada di mall juga turut menyemarakan dunia fashion dan juga pendirian boutique diberbagai tempat cukup menjadikan bukti kemajuan pada bidang fashion. Namun, dengan adanya toko, departement store serta boutique sebagai tempat untuk berjualan tidak dapat menjangkau kepada pasar yang lebih luas karena sistem penjualannya adalah sistem konvensioanal hanya ditempat itu berada sehingga tidak memungkinkan orang-orang dapat mengetahui berbagai produk fashion yang dijual.

Menanggapi permasalahan diatas bahwa setiap bisnis harus melakukan berbagai upaya dalam memajukan usaha yang dijalankan khususnya Anita Kurnia Boutique sebagai perusahaan yang bergerak dibidang fashion harus memiliki strategi penjualan untuk meningkatkan omset penjualan dengan melalui e-commerse. Dengan e-commerce dapat dimanfaatkan untuk memasarkan dan menjual barang dan jasa melalui koneksi internet. 


\section{METODOLOGI PENELITIAN}

Metode yang digunakan pada
pengembangan perangkat lunak in
menggunakan model waterfall (Rosa dan
Shalahuddin, 2014:28) metode yang diambil
yaitu:

Analisis kebutuhan perangkat lunak yang meruapakan proses pengumpulan kebutuhan dilakukan secara intensif untuk menspesifikasikan kebutuhan perangkat lunak agar dapat dipahami perangkat lunak seperti apa yang dibutuhkan oleh user. Spesifikasi kebutuhan perangkat lunak pada tahap ini perlu untuk didokumentasikan.

Teknik Pengumpulan Data

Sedangkan metode pengumpulan data yang digunakan dalam penulisan tugas akhir ini, penulis menggunakan metode pengumpulan data sebagai berikut:

Pengamatan (Observasi)

Riduwan (2012:30) mengemukakan bahwa "Observasi yaitu melakukan pengamatan secara lansung ke objek penelitian untuk melihat dari dekat kegiatan yang dilakukan". Metode ini dilakukan untuk mengetahui bagaimana perkembangan yang sebenarnya.

Wawancara (interview)

Menurut Sugiyono

(2008:137)

"Wawancara digunakan sebagai teknik pengumpulan data apabila peneliti ingin melakukan studi pendahuluan untuk menemukan permasalahan yang harus diteliti, dan juga apabila peneliti ingin mengetahui halhal dari responden yang lebih mendalam dan jumlah respondennya sedikit/kecil". Wawancara dapat dilakukan secara terstruktur maupun tidak terstruktur, dan dapat dilakukan nmelalui tatap muka (face to face) maupun dengan menggunakan telepon.

Studi Pustaka (Literature)

Menurut Sujarweni (2014:23) "Studi pustaka merupakan kajian dari bahan documenter yang tertulis, bisa berupa teks, surat kabar, majalah, surat-surat dan lainnya, untuk dianalisis dan menentukan tingkat pencapaian pemahaman terhadap topic tertentu". Studi kepustakaan dilakukan dengan mengumpulkan kepustakaan yang berhubungan dengan pembuatan website secara umum, kepustakaan diperoleh dari buku pustaka, e-book, dan artikel internet.

\section{Ruang Lingkup}

Adapun ruang lingkup dalam laporan tugas akhir ini penulis membatasi permasalahan yang akan dibahas yaitu:

Admin diberi hak akses untuk mengelola halaman admin, halaman kategori, halaman produk, halaman detail produk, halaman kontak, halaman cara belanja, dan halaman konfirmasi pembayaran.

User diberi hak akses dapat melihat home, melihat produk, melihat kontak, dapat menambahkan testimoni, dan cara melalukan pendaftaran sebagai member di anita kurnia boutique.

Member diberi hak akses dapat melihat home, melihat produk, melihat kontak, dapat menambahkan testimoni, cara melakukan pemesanan produk yang diinginkan, dan konfirmasi pembayaran di anita kurnia boutique.

Menjelaskan kronologis penelitian, termasuk desain penelitian, prosedur penelitian (dalam bentuk algoritma, Pseudocode atau lainnya), bagaimana untuk menguji dan akuisisi data. Deskripsi dari program penelitian harus didukung referensi, sehingga penjelasan tersebut dapat diterima secara ilmiah.

\section{HASIL DAN PEMBAHASAN}

\section{Analisa Kebutuhan}

Untuk mempermudah analisa sistem dalam menentukan keseluruhan kebutuhan secara lengkap, maka analisis membagi kebutuhan sistem ke dalam dua jenis. Jenis pertama adalah kebutuhan fungsional (functional requirement), dan yang kedua adalah kebutuhan nonfungsional (nonfunctional requirement) (Fatta, 2007:63).

1. Kebutuhan Fungsional

Kebutuhan fungsional adalah jenis kebutuhan yang berisi proses-proses apa saja yang nantinya dilakukan oleh sistem. Kebutuhan fungsional juga berisi informasiinformasi apa saja yang harus ada dan dihasilkan oleh sistem (Fatta, 2007:63).

a. Analisa Kebutuhan Admin

1) Tersedianya web browser (internet explorer, google chrome, mozilla firefox, dll) untuk bisa mengakses website.

2) Adanya koneksi internet untuk bisa akses website.

3) Admin harus melakukan login terlebih dahulu untuk dapat mengakses halaman admin dengan memasukkan username dan password.

4) Admin dapat melihat, mengubah, menambah dan menghapus halaman website.

5) Admin dapat logout setelah menggunakan halaman website.

b. Analisa Kebutuhan User 
1) Tersedianya web browser (internet explorer, google chrome, mozilla firefox,dll) untuk bisa mengakses website.

2) Adanya koneksi internet untuk bisa akses website.

3) User dapat melihat halaman website.

4) User dapat melihat informasi lengkap tentang Anita Kurnia Boutique.

6) User dapat memberikan testimoni.

c. Analisa Kebutuhan Member

1) Tersedianya web browser (internet explorer, google chrome, mozilla firefox,dll) untuk bisa mengakses website.

2) Adanya koneksi internet untuk bisa akses website.

3) Member dapat memilih menu pada bagian atas untuk dapat melihat tampilan yang diinginkan.

4) Member dapat logout setelah menggunakan halaman website.

2. Kebutuhan Non-Fungsional

Kebutuhan ini adalah tipe kebutuhan yang berisi properti perilaku yang dimiliki oleh sistem (Fatta, 2007:63).

a. Operasional

1) Digunakan untuk sistem operasi Microsoft Windows 7.

2) Spesifikasi komputer Processor Intel Atom Inside.

3) Kebutuhan memori DDR2 1GB.

b. Security

1) Admin harus login terlebih dahulu agar dapat mengakses website Anita Kurnia Boutique dengan memasukkan username dan password agar privasi pengguna tetap aman.

2) Admin harus logout begitu setelah selesai mengakses website Anita Kurnia Boutique.

c. Informasi

Informasi ini digunakan untuk memberitahu admin apabila username dan password yang dimasukkan salah.

Pada bagian ini, dijelaskan hasil penelitian dan pada saat yang sama diberikan pembahasan yang komprehensif. Hasil dapat disajikan dalam angka, grafik, tabel, dan lain-lain yang membuat pembaca memahami dengan mudah. Pada bagian ini ditekankan nilai baru dari penelitian yang memuat inovasi, serta implikasinya. Pembahasan dapat dibuat dalam beberapa subbab.

\section{Perancangan Perangkat Lunak}

Perancangan perangkat lunak merupakan sebuah proses yang berkelanjutan dari analisa dan didalamnya melakukan identifikasi hasil analisa serta menghasilkan konsep dasar untuk kepentingan pengembangan perangkat lunak.

\section{Rancangan Antar Muka}

1. Rancangan Antar Muka Halaman Admin a. Rancangan Antar Muka Login Admin

Nama File : login.php

Bahasa : php.

Script

Fungsi : Untuk dapat mengakses halaman program administrator.

Proses : Masukkan username dan password kemudian klik masuk.

Penjelasan : Halaman ini merupakan halaman untuk login agar dapat masuk ke halaman admin.

Bentuk :

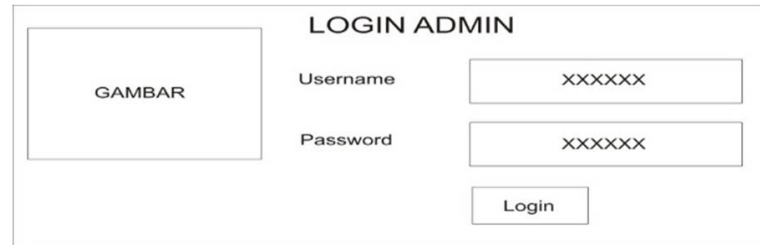

Sumber : Hasil Penelitian (2018)

Gambar I

Rancangan Tampilan Login

Nama File $\quad: \quad$ main.php

Bahasa Script $\quad$ : php dan css.

Fungsi

Proses

Penjelasan

Bentuk

Untuk menampilkan
halaman program
yang dipanggil
pertama kali saat
dijalankan.
Setelah melakukan
login admin maka
akan muncul
halaman home
admin.
Halaman
merupakan
halaman awal pada
halaman admin
yang berisi link-link
untuk menambah
data, menghapus
dan mengedit data
admin.

Untuk menampilkan pertama kali saat halaman home

ini merupakan halaman awal pada halaman admin yang berisi link-link untuk menambah data, menghapus admin. akan muncu 


\begin{tabular}{|c|c|}
\hline & HEADER \\
\hline $\begin{array}{l}\text { HOME } \\
\text { AOMIN } \\
\text { DATAPROUNSI } \\
\text { DATA KaTEGORI } \\
\text { DATA BARANG } \\
\text { PELANGGAN } \\
\text { TESTMONAL } \\
\text { DATA PEMESANAN } \\
\text { KONFIRMASI TRANSFER } \\
\text { LADORAN } \\
\text { LOGOUT }\end{array}$ & $\begin{array}{c}\text { Terima Kasih Sudah Login } \\
\text { Selamat Bekerja! } ;\end{array}$ \\
\hline
\end{tabular}

Sumber: Hasil Penelitian (2018)

Gambar II

Rancangan Tampilan Home

\section{Rancangan Antar Muka Password Admin}

Nama File : password_admin.php

Bahasa : php dan css.

Script

Fungsi : Untuk mengganti password admin.

Proses : Setelah melakukan login admin maka akan muncul halaman home admin, kemudian klik password admin.

Penjelasan : Halaman ini merupakan halaman untuk mengedit

Bentuk password admin.

\section{GANTI PASSWORD ADMIN \\ Username \\ Password Lama \\ Password Baru

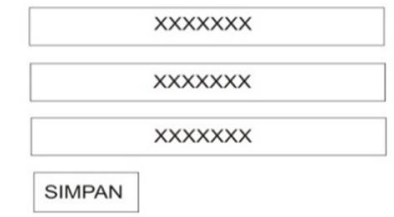 \\ Sumber : Hasil Penelitian (2018) \\ Gambar III \\ Rancangan Tampilan Password Admin}

\section{Rancangan Antar Muka Data Barang}

Nama File : barang_add.php

Bahasa : php dan css.

Script

Fungsi : Untuk menyimpan data produk yang dijual.

Proses : Setelah melakukan login admin maka akan muncul halaman home admin, kemudian klik data barang.

Penjelasan : Halaman ini merupakan halaman untuk menambah data, menghapus dan mengedit data.

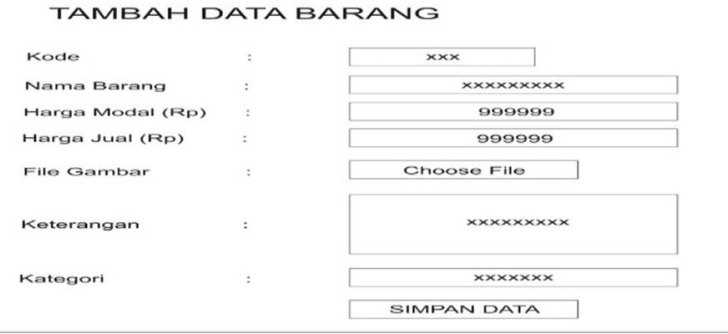

Sumber : Hasil Penelitian (2018)

Gambar IV

Rancangan Tampilan Tambah Data Barang

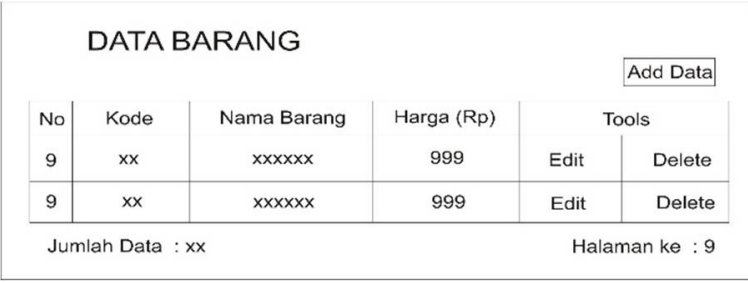

Sumber : Hasil Penelitian (2018)

Gambar V

Rancangan Tampilan Data Barang

\section{Rancangan Basis Data}

Perancangan basis data yang dihasilkan dari perancangan website Anita Kurnia Boutique menghasilkan pemetaan tabeltabel yang digambarkan pada gambar IV dan gambar V :

1. Entity Relationship Diagram (ERD)

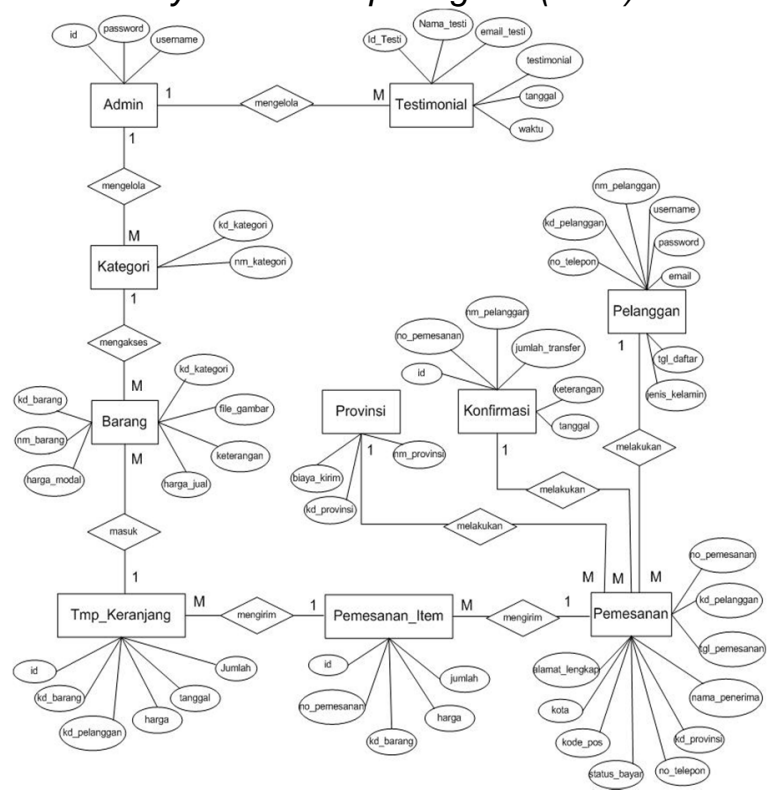

Sumber : Hasil Penelitian (2018)

Gambar VI

Entity Relationship Diagram 
2. Logical Relationship Structure (LRS)

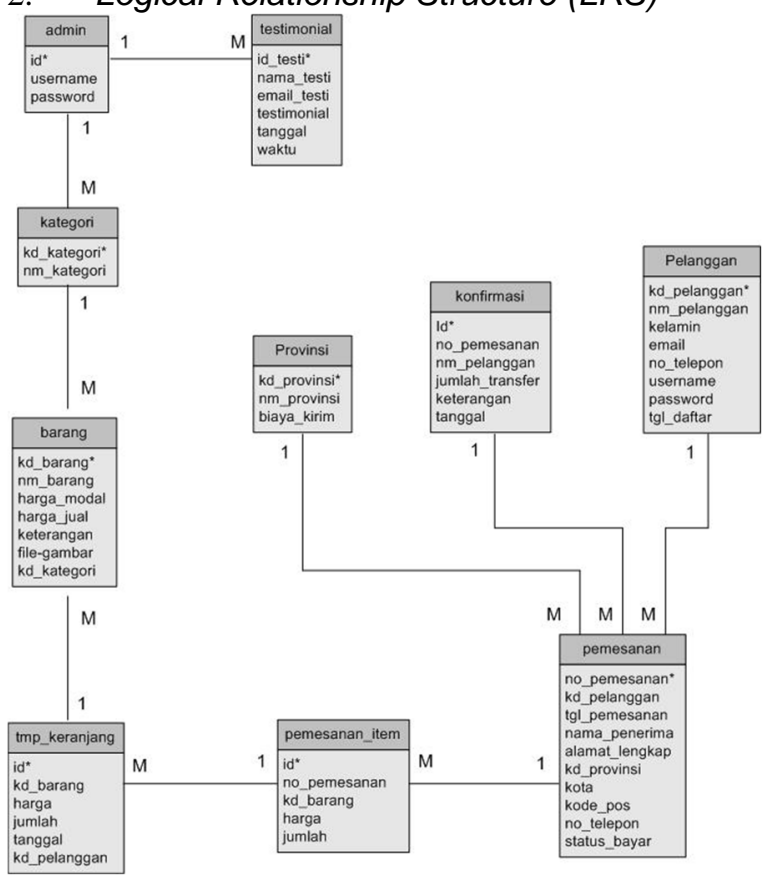

Sumber : Hasil Penelitian (2016)

Gambar III.33

Logical Relationship Structure

\section{Spesifikasi File}

Pembuatan website Anita Kurnia Boutique memerlukan database yang berguna untuk media penyimpanan data informasi. Database tersebut terdiri dari beberapa tabel yang masing-masing berisi data-data yang nantinya disimpan dan diolah untuk kemudian ditampilkan lagi pada halaman web tersebut. Adapun tabel basis data yang digunakan dalam aplikasi website ini adalah sebagai berikut:

a. Spesifikasi File Admin

Nama Tabel

Fungsi menyimpan data login admin.

Media File

Record Key

Software

MySQL/PhpMyAdmin

Tabel 1

Spesifikasi File Tabel Admin

\begin{tabular}{|l|l|l|l|l|}
\hline Field & Type & $\begin{array}{c}\text { Siz } \\
\boldsymbol{e}\end{array}$ & $\begin{array}{l}\text { Keteran } \\
\text { gan }\end{array}$ & Extra \\
\hline Id & Int & 2 & $\begin{array}{l}\text { Primary } \\
\text { Key }\end{array}$ & $\begin{array}{l}\text { Auto_incre } \\
\text { ment }\end{array}$ \\
\hline $\begin{array}{l}\text { Userna } \\
\text { me }\end{array}$ & $\begin{array}{l}\text { Varc } \\
\text { har }\end{array}$ & 20 & & \\
\hline $\begin{array}{l}\text { Passw } \\
\text { ord }\end{array}$ & $\begin{array}{l}\text { Varc } \\
\text { har }\end{array}$ & 20 & & \\
\hline
\end{tabular}

Sumber: Hasil Penelitian (2018) b. Spesifikasi File Barang

Nama Tabel

: Barang.

Fungsi

Untuk

menyimpan data barang.

Media File

Record Key

: Harddisk.

Software

MySQL/PhpMyAdmin.

Tabel 2

Spesifikasi File Tabel Barang

\begin{tabular}{|c|c|c|c|c|}
\hline Field & Type & $\begin{array}{l}\text { Si } \\
z e\end{array}$ & $\begin{array}{c}\text { Keteran } \\
\text { gan }\end{array}$ & Extra \\
\hline $\begin{array}{l}\text { Kd_bara } \\
\text { ng }\end{array}$ & Char & 5 & $\begin{array}{l}\text { Primary } \\
\text { Key }\end{array}$ & $\begin{array}{l}\text { Auto_incr } \\
\text { ement }\end{array}$ \\
\hline $\begin{array}{l}\mathrm{Nm} \text { Nbar } \\
\text { ang }\end{array}$ & $\begin{array}{l}\text { Varc } \\
\text { har }\end{array}$ & 30 & & \\
\hline $\begin{array}{l}\text { Harga } \\
\text { modal }\end{array}$ & Int & 12 & & \\
\hline $\begin{array}{l}\text { Harga_ju } \\
\text { al }\end{array}$ & Int & 12 & & \\
\hline $\begin{array}{l}\text { Keterang } \\
\text { an }\end{array}$ & Text & & & \\
\hline $\begin{array}{l}\text { File_ga } \\
\text { mbar }\end{array}$ & $\begin{array}{l}\text { Varc } \\
\text { har }\end{array}$ & $\begin{array}{l}10 \\
0\end{array}$ & & \\
\hline $\begin{array}{l}\text { Kd_kate } \\
\text { gori }\end{array}$ & Char & 4 & & \\
\hline
\end{tabular}

Sumber: Hasil Penelitian (2018)

\section{c. Spesifikasi File Kategori}
Nama Tabel
: Kategori.
Fungsi
: Untuk
menyimpan data kategori.
Media File
- Harddisk
Record Key
: Kd_Kategori.
Software
MySQL/PhpMyAdmin.
Tabel 3
Spesifikasi File Tabel Kategori

\begin{tabular}{|l|l|l|l|l|}
\hline \multicolumn{1}{|c|}{ Field } & Type & $\begin{array}{l}\text { Si } \\
\text { ze }\end{array}$ & $\begin{array}{l}\text { Keteran } \\
\text { gan }\end{array}$ & Extra \\
\hline $\begin{array}{l}\text { Kd_kate } \\
\text { gori }\end{array}$ & Char & 4 & $\begin{array}{l}\text { Primary } \\
\text { Key }\end{array}$ & $\begin{array}{l}\text { Auto_incre } \\
\text { ment }\end{array}$ \\
\hline $\begin{array}{l}\text { Nm_kat } \\
\text { egori }\end{array}$ & $\begin{array}{l}\text { Varc } \\
\text { har }\end{array}$ & 25 & & \\
\hline
\end{tabular}

Sumber : Hasil Penelitian (2018)

\section{d. Spesifikasi File Konfirmasi}

Nama Tabel : Konfirmasi.

Fungsi : Untuk

menyimpan data konfirmasi.

Media File : Harddisk.

Record Key : :Id.

Software

MySQL/PhpMyAdmin. 
Tabel 4

Spesifikasi File Tabel Konfirmasi

\begin{tabular}{|l|l|l|l|l|}
\hline \multicolumn{1}{|c|}{ Field } & Type & $\begin{array}{l}\text { Siz } \\
\boldsymbol{e}\end{array}$ & $\begin{array}{l}\text { Keterang } \\
\text { an }\end{array}$ & \multicolumn{1}{c|}{ Extra } \\
\hline Id & Int & 4 & $\begin{array}{l}\text { Primary } \\
\text { Key }\end{array}$ & $\begin{array}{l}\text { Auto_increm } \\
\text { ent }\end{array}$ \\
\hline $\begin{array}{l}\text { No_pemesa } \\
\text { nan }\end{array}$ & $\begin{array}{l}\text { Varch } \\
\text { ar }\end{array}$ & 8 & & \\
\hline $\begin{array}{l}\text { Nm_pemesa } \\
\text { nan }\end{array}$ & $\begin{array}{l}\text { Varch } \\
\text { ar }\end{array}$ & 35 & & \\
\hline $\begin{array}{l}\text { Jumlah_tran } \\
\text { sfer }\end{array}$ & Int & 12 & & \\
\hline Keterangan & Text & & & \\
\hline Tanggal & Date & & & \\
\hline
\end{tabular}

Sumber : Hasil Penelitian (2018)

e. Spesifikasi File Pelanggan

Nama Tabel : Pelanggan.

Fungsi

: Untuk

menyimpan data pelanggan.

Media File

: Harddisk.

Record Key

Kd_Pelanggan.

Software

MySQL/PhpMyAdmin.

Tabel 5

Spesifikasi File Tabel Pelanggan

\begin{tabular}{|c|c|c|c|c|}
\hline Field & $\begin{array}{c}\text { Typ } \\
e\end{array}$ & $\begin{array}{l}\text { Si } \\
z e\end{array}$ & $\begin{array}{c}\text { Ketera } \\
\text { ngan }\end{array}$ & Extra \\
\hline $\begin{array}{l}\text { Kd_pelan } \\
\text { ggan }\end{array}$ & Char & 6 & $\begin{array}{l}\text { Primary } \\
\text { Key }\end{array}$ & $\begin{array}{l}\text { Auto_incr } \\
\text { ement }\end{array}$ \\
\hline $\begin{array}{l}\text { Nm_pela } \\
\text { nggan }\end{array}$ & $\begin{array}{l}\text { Varc } \\
\text { har }\end{array}$ & 35 & & \\
\hline Kelamin & $\begin{array}{l}\text { Enu } \\
m\end{array}$ & & & \\
\hline Email & $\begin{array}{l}\text { Varc } \\
\text { har }\end{array}$ & 30 & & \\
\hline $\begin{array}{l}\text { No_telep } \\
\text { on }\end{array}$ & $\begin{array}{l}\text { Varc } \\
\text { har }\end{array}$ & 12 & & \\
\hline $\begin{array}{l}\text { Usernam } \\
e\end{array}$ & $\begin{array}{l}\text { Varc } \\
\text { har }\end{array}$ & 20 & & \\
\hline Password & $\begin{array}{l}\text { Varc } \\
\text { har }\end{array}$ & 20 & & \\
\hline$\underset{r}{\text { Tgl_dafta }}$ & Date & & & \\
\hline
\end{tabular}

Sumber : Hasil Penelitian (2018)

\section{f. Spesifikasi File Pemesanan}
Nama Tabel
: Pemesanan.
Fungsi
Untuk
menyimpan data saat ada transaksi
pemesanan.
Media File
: Harddisk.
Record Key
No_Pemesanan.
Software
MySQL/PhpMyAdmin.

\section{Implementasi dan Pengujian Unit}

1. Implementasi Rancangan Antar Muka Implementasi rancangan antar muka pada rancangan Website Anita kurnia Boutique. Berdasarkan hasil rancangan antar muka adalah sebagai berikut:

a. Halaman Login Admin

Admin dapat melakukan login terlebih dahulu dengan mengisikan username dan password agar dapat mengakses ke halaman admin serta melakukan pengelolaan halaman utama melalui menu-menu yang tersedia. Berikut tampilannya:

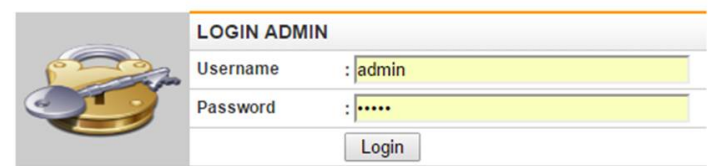

Sumber : Hasil Penelitian (2018)

$$
\begin{gathered}
\text { Gambar } 7 \\
\text { Login Admin }
\end{gathered}
$$

Halaman Data Barang Halaman ini admin dapat menambahkan barang, mengedit maupun menghapus barang. Berikut tampilannya:

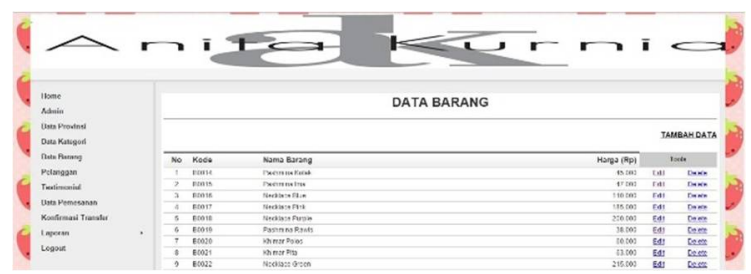

Sumber : Hasil Penelitian (2018)

Gambar 8

Halaman Data Barang

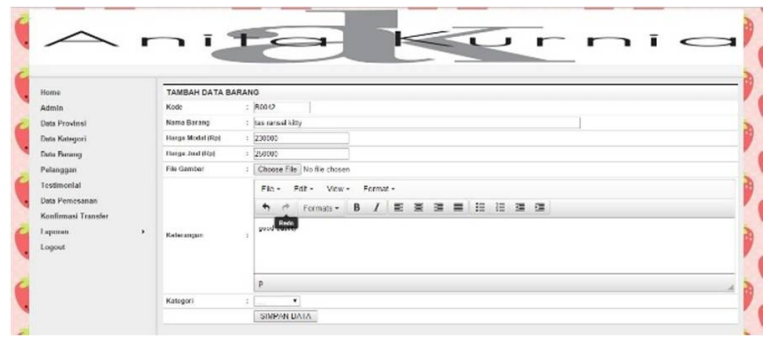

Sumber : Hasil Penelitian (2018)

Gambar 9

\section{KESIMPULAN}

Pembuatan Perancangan Website Sistem Informasi Penjualan pada Anita Kurnia Boutique Malang. Berdasarkan hasil analisa dan pengamatan penulis selama mengerjakan tugas akhir ini, maka dalam hal ini dapat diambil kesimpulan sebagai berikut:

1. Dengan adanya website ini dapat memudahkan Anita Kurnia Boutique dalam 
memberikan informasi kepada user dan diharapkan dapat meningkatkan omset penjualan Anita Kurnia Boutique.

2. Hasil pengujian sistem dengan metode black box menunjukkan website tersebut sesuai harapan.

3. Website yang dibangun menggunakan Dreamweaver CS6, Photoshop CS3 dan database MySQL yang memudahkan dalam pembuatan website.

Saran

Saran diperlukan untuk membangun sebuah karya tulis menjadi semakin lengkap dan sempurna. Berdasarkan kesimpulan diatas serta kelemahan yang ada berdasarkan proses pembuatan website Sistem Informasi Penjualan pada Anita Kurnia Boutique Malang dari awal sampai akhir, maka penulis mempunyai beberapa saran untuk menyempurnakan pembuatan website sebagai berikut:

1. Penambahan sistem keamanan website untuk meningkatkan keamananan admin dan user dalam melakukan transaksi.

2. Website E-Commerce yang baik harus mempunyai sistem yang memiliki tampilan menarik.

3. Diharapkan dapat dilengkapi fasilitas peta, sehingga memudahkan pengujung untuk mengetahui letak tempat butik yang ada di Malang.

4. Diharapkan Website Anita Kurnia Boutique ini dapat di hostingkan.

5. Pengelolaan Website hendaknya selalu di update agar menarik perhatian pengujung.

\section{DAFTAR REFERENSI}

Arief, M. Rudyanto. 2011. Pemograman Web Dinamis Menggunakan PHP dan MySQL. Yogyakarta: C.V ANDI OFFSET (penerbit ANDI).

Binanto, I. 2010. Multimedia Digital Dasar Teori + Pengembangannya. Yogyakarta: C.V ANDI OFFSET (Penerbit ANDI)

Fatta, H. A. 2007. Analisis dan Perancangan Sistem Informasi Untuk Keunggulan Bersaing Perusahaan dan Organisasi Modern. Yogyakarta: C.V ANDI OFFET (Penerbit ANDI).

Fatta, H. A. 2007. Analisis dan Perancangan Sistem Informasi Untuk Keunggulan Bersaing Perusahaan dan Organisasi Modern. Yogyakarta: C.V ANDI OFFSET (Penerbit ANDI).

Frieyadi. 2007. Belajar Sendiri Pemograman Database Menggunakan FoxPro (.0. Jakarta: PT Elex Media Komputindo.

Hidayatulloh, Taufiq, A. 2012. Rekayasa Foto Digital dan Teknik Membuat Animasi dengan Adobe Photoshop CS6. Yogyakarta: PENERBIT GAVA MEDIA.

Jovan, FN. 2007. Panduan Praktis Membuat Web dengan PHP untuk Pemula. Jakarta: Mediakita.

Juju, Dominikus. 2010. Cara Mudah Buka Toko Online dengan Wordpress + WP ECOMMERCE. Yogyakarta: ANDI.

Kadir, A. 2008. Dasar Pemograman Web Dinamis Menggunakan PHP. Yogyakarta: C.V ANDI OFFSET (Penerbit ANDI).

Kristanto, Andri 2008. Perancangan Sistem Informasi dan Aplikasinya. Yogyakarta: PENERBIT GAVA MEDIA.

Kurniawan, R. 2010. PHP dan MySQL Untuk Orang Awam. Palembang: Maxikom.

Kusrini. 2007. Strategi Perancangan dan Pengelolaan Basis Data. Yogyakarta: C.V ANDI OFFSET (penerbit ANDI).

Kusnadi, M. 2011. Kamus Pintar Komputer dan Internet. Surabaya: Bintang Usaha Jaya.

Kustianingsih, Yeni dan Devie Rosa Anamisa. 2011. Pemograman Basis Data Berbasis Web Menggunakan PHP \& MySQL. Yogyakarta: GRAHA ILMU.

Masrur, M. 2009. Internet Supermudah Untuk Siapa Saja. Yogyakarta: BOOKMARKS.

Nugroho, Bunafit. 2008. Latihan Membuat Aplikasi Web PHP dan MySQL dengan Dreamweaver MX $[6,7,2004)$ dan 8. Yogyakarta: PENERBIT GAYA MEDIA.

Puspitosari, H. A. 2010. Membangun Website Interaktif dengan Adobe Creative Suite 5. Yogyakarta: Skripta Media Creative.

Riduwan. 2012. Skala Pengukuran VariabelVariabel Penelitian. Jawa Barat: ALFABETA.

S, Rosa A dan M. Shalahuddin. 2013. Rekaya Perangkat Lunak Terstruktur dan Berorientasi Objek. Bandung: Informatika Bandung.

Sadeli, M. 2013. 7 Jam Belajar Interaktif Dreamweaver CS6 Untuk Orang Awam. Palembang: Maxikom.

Sibero, A. F. 2011. Kitab Suci Web Programming. Yogyakarta: Mediakom.

Sidik, Betha. 2011. JavaScript. Bandung: Informatika Bandung. 